\title{
Kaiwa Learning Using Role Play Method On Students Of The Faculty Of Health Science Assyafiyah University In Improving Japanese Speaking Skills
}

\author{
Alo Karyati, Yelni Rahmawati \\ Fakultas Ilmu Sosial dan Ilmu Budaya, Universitas Pakuan \\ email: alokaryati1974@gmail.com \\ alo.karyati@unpak.ac.id
}

Received: 13 August 2021; Revised: 02 October 2021; Accepted: 14 December 2021

DOI: http://dx.doi.org/10.37905/aksara.8.1.227-236.2022

\begin{abstract}
The aims of this research to see the effectiveness of the role play method in improving Japanese speaking skills in students of the Faculty of Health Sciences, Assyafiiyah Islamic University. Speaking ability is very important in teaching Kaiwa/Japanese Conversation. Speaking is a medium of communication to convey ideas, intentions, and messages to others. Through speaking we can convey ideas and intentions to the other person. The formulation of the problem in this research are: (1) Can the role play method using role cards improve speaking skills? (2) How is the speaking ability of the students of the Faculty of Health Sciences, Assyafiiyah Islamic University before and after using the role play method? (3) Are there any differences in speaking ability before and after using the role play method? (4) What are the obstacles faced by students when learning Kaiwa using the role play method with role cards? The research method used in this paper is true experimental. In this research, the researcher did not conduct class control, the research only focused on 1 class. Treatment was carried out for 5 times. The population of this research were students of the Faculty of Health Sciences, Assyafiiyah Islamic University with a sample of 20 students. The data analysis technique uses the SPSS application. The data to be analyzed is the value of pretest, posttest and also a questionnaire from google form. The results of this research are expected to be useful for Kaiwa teachers in general, and especially for students who are studying Japanese.
\end{abstract}

Keywords: Kaiwa, Role Play, Role Card, and Speaking Ability

\section{PENDAHULUAN}

Bahasa merupakan alat komunikasi yang paling penting dalam kehidupan kita, melaui bahasa kita dapat menyampaikan sesuatu kepada lawan bicara. Menurut Chaer (2015: 30) bahasa adalah alat verbal yang digunakan untuk berkomunikasi, sedangkan berbahasa adalah proses penyampaian informasi dalam berkomunikasi itu. Mengenai bahasa diterangkan pulan oleh Hidayat (2006:21) bahasa merupakan salah satu aspek yang tidak dapat dipisahkan dari seluruh kehidupan manusia. Tanpa bahasa manusia tidak bisa mengetahui dan mengeri apa yang diucapkan, diinginkan dan dimaksudkan oleh orang lain dan sekitarnya (Toliwongi, 2021. Jadi dapat disimpulkan bahwa bahasa merupakan alat yang menghubungkan antar manusia satu dengan manusia lain. Dalam mempelajari bahasa kita mengenal 4 kemampuan berbahasa, yeitu menyimak, membaca, menulis dan berbicara. 4 kemampuan berbahasa ini satu sama lain memiliki peranan yang sangat penting dan satu sama lain saling berhubungan. Dari ke emapat kemampuan berbahasa tersebut, kemampuan berbicara merupakan hal yang paling berhubungan dengan kemamouan berbahasa. Menurut (Sudjianto: 2010:99) dalam (Soemarmi, 2017) bahwa di dalam pembelajaran bahasa juga ada beberapa faktor yang perlu diperhatikan, seperti: (1) peserta bicara, (2) tempat dan waktu keberlangsungan 
interakasi berbahasa, (3) topik pembicaraan, (4) sarana pembicaraan, (5) tujuan pembicaraan, (6) perasaan yang berlangsung dalam pembicaraan.

Berbicara merupakan keterampilan berbahasa yang bersifat produktif yang melibatkan aspek kebahasaan (pelafalan, kosa kata, dan struktur) dan aspek nonkebahasaan (siapa lawan bicaranya, latarnya, peristiwanya, serta tujuannya) (Slamet, 2007:206) dalam (Nurwida, 2016). Menurut (Barley, 1996) dalam ( Tolowongi, 2021) berbiacra merupakan keterampilan yang paling harus dikuasai dalam kegatan berbahasa. Hal ini juga dikemukakan oleh Tarigan (1996) Dalam (Tolowongi, 2006) mengartikan bahwa berbicara sebagai kemampuan mengucapakan bunyi-bunyi artikulasi atau katakata untuk mengekspresikan, mengatakan serta menyampaikan pikiran, gagasan, dan perasaan. Hal ini pun dikemukan juga oleh ( Iskandarwasid \& Sunendar, 2008: 241). Definisi berbicara juga dikemukakan oleh Brown dan Yule, dalam (Taufina \& Khaeroes, 2019) bahwa berbicara merupakan bunyi-bunyi bahasa untuk mengekspresikan atau menyampaikan pikiran atau perasaan secara lisan. Sedangkan keterampilan berbicara adalah kemampuan mengekspresikan berbagai pikiran serta pendapat sendiri yang dikemukakan secara lisan." Terdapat dua sudut pandang yaitu secara sempit penjelasan tersebut bermakna kemampuan mengekspresikan kalimat berdasarkan kaidahkaidah kebahasaan secara lisan, sedangkan secara luas bermakna sama dengan kemampuan bercakap-cakap Ogawa (1982:611) dalam (Restoeningrum, 2014).

Menurut (Iskandarwassid \& Sunendar, 2018: 286) ada bebererapa konsep yang harus diperhatikan oleh pengajar sebelum mengajar, diantaranya: (1) berbicara dan menyimak adalah dua kegiatan resiprokal. (2) berbicara adalah proses berkomunikasi inidividu.(3) berbicara adalah ekspresi kreatif. (4) berbicara adalah tingkah laku, (5) berbicara dipengaruhi kekayaan pengalaman, (6) berbicara merupakan sarana memperluas cakrawala, (7) berbicara adalah pancaran pribadi.

Akhir-akhir ini jumlah pembelajar bahasa Jepang di Indonesia semakin meningkat, banyak Universitas-universitas baik swasta mupun negeri membuka jurusan bahasa Jepang, sekolah-sekolah menengah atas seperti SMA dan SMK pun banyak yang menajdikan bahasa Jepang sebagai muatan lokal, lembaga -lembaga kursus di Indonesia makin marak bermunculan membuka kelas Bahasa Jepang. Pemerintah Jepang yang membuka lowongan pekerjaan bagi orang Asing, membuat banyak masyarakat Indonesia yang semakin tertarik belajar bahasa Jepang. Lowongan-lowongan kerja di Jepang terdiri dari banyak sektor terbuka untuk untuk orang asing, seperti, bidang Industri, pertanian, Kesehatan (Caregiver dan perawat), perhotelan dan lain-lain. Ini tentu saja membuat bahasa Jepang semakin populer di Indonesia dan menjadi incaran untuk dipelajari. Apalagi situasi sekarang ini lapangan kerja di Indonesia makin sempit.

Seperti halnya di Universitas Assyafiiyah Jakarta yang memberikan pelajaran bahasa Jepang kepada mahasiswa Fakultas Ilmu Kesehatan, karena bertujuan agar lulusan mahasiwanya dapat bekerja di jepang pada bagian Kesehatan, seperti perawat di rumah sakit atau perawat di panti Jompo. Karena latar belakang mahasiswa Fakultas Ilmu kesehaatan ini bukan dari bahasa Jepang, Pelajaran bahasa Jepang bukan yang inti selain bidang keperawatan dan sejenisnya. Sehingga saat pembelajarannya memerlukan teknik yang dapat membuat mahasiswanya mampu berbicara bahasa Jepang lebih cepat dari pembelajar yang memang mengambil jurusan Bahasa Jepang. Berdasarkan hal tersebut peneliti mencoba menggunakan metode role play pada saat pembelajar kaiwanya. Mengapa peneliti menerapkan metode role play pada mahasiswa Fakultas 
Ilmu Kesehatan Universitas Islam Assyafiiyah? Ini dikarena metode ini samgat menarik untuk diajarkan pada mahasiswa yang latar belakangnya bukan dari jurusan Bahasa jepang.

Role play adalah salah satu metode pembelajaran kemampauan berbicara dalam Bahasa Asing, yaitu dalam pembelajaran kaiwa. Banyak pengajar Bahasa Jepang yang menggunakan metode ini ketika mengajar kaiwa. Role play/bermain peran merupakan kegiatan pembelajaran kemampuan berbicara dengan cara bermain peran, yaitu 2 siswa melakukan latihan percakapan di depan kelas berdasarkan tema yang diberikan pengajar. Kobayashi (2001:70) dalam Restoeningrum (2014) mengungkapkan bahwa role play adalah kegiatan berdialog yang mengikuti suatu latar dan peran "Role play adalah suggestopedia yang mendukung teori suggestologi, yaitu kegiatan kelas yang kelas yang digunakan untuk mempermudah belajar, membebaskan exspresi (kejiwaan) siswa dengan cara menentukan peran dan latar". Dalam pembelajaran role play/bermain peran diperlukan bermacam-macam teknik. Seperti yang diungkapkan oleh Okazaki, dkk (1987:14) dalam Restoeningrum (2014) bahwa tahap-tahap kegiatan role play. adalah seperti berikut: (1) Tahap persiapan : (a) menjelaskan isi tujuan, dan prosedur role play kepada siswa dengan baik,(b) Membagi peran. Guru mengambil keputusan agar hasil yang diinginkan tercapai. (c) membagikan kartu peran dan memberi waktu persiapan kepada siswa. (2) Tahap pelaksanaan: (a) Guru berkeliling di antara para siswa, melihat siapa yang akan tampil dengan lancar (b) Guru mengajarkan ungkapan (hyoogen) dengan perlahan-lahan apabila ada kelompok yang tidak tampil karena tidak mengerti.

(3) Alat pementasan: (a) Menanyakan kesan tentang role play yang baru dipentaskan,

(b) Menanyakan bagaimana gaya pementasan, (c) Membicarakan teknik role play tersebut dengan siswa. Menurut Joyce dkk (2009: 341) dalam Ningsih dkk (2019) mengatakan bahwa maanfat role play dalam pembelajaran, yaitu (1) siswa dapat meningkatkan kemmapuan dalam mengenali dan memperhitungkan perasaanya sendiri serta perasaan orang lain. hal ini berarti ssiwa dapat memiliki perilaku baru dalam menghadapi situasi sulit yanf tengah dihadapi dan siswa dapat meningkatkan skill memecahkan masalah. (2) Role play mampu merangsang timbulnya beberapa aktivutas . Artinya siwa dapat mengespos nilai-nilai, perasaan, solusi masalah, dan tingkah laku yang ada dan terpendam dari siswa.

\section{METODE PENELITIAN}

Jenis penelitian ini adalah eksprimenment. Pada penelitian ini peneliti tidak mengadakan kelas kontrol. Jadi peneltian fokus ke dalam 1 kelas. Tujuan penelitian eksperimental adalah untuk mengukur sejauhmana metode yang dihuunakan efektif dalam meningkatkan kemampuanDesain penelitian yang peneliti pakai adalah Pretest dan Postest group. Pada desain ini, observasi dilakukan sebanyak 2 kali yaitu sebelum eksperimen dan sesudah eksperimen. Pretest dilakukan diawal eksperimen atau sebelum treatnent, peneliti memberikan tes berupa tes lisan. Tes lisan berupa tanya jawab dalam bahasa Jepang. Setelah pretest dan postest dilakukan, maka akan terlihat efektivitas eksperimen dan treatment selama melakukan penelitian ini. Teknik pengumpulan data dilakukan melalui google form yang berisi 10 kalimat pernyataan.Teknik analisis data menggunakan aplikasi SPSS dan hasil dari angket google form. 


\section{HASIL DAN PEMBAHASAN}

HASIL

Berdasarkan grafik nilai diatas terlihat bahwa kemampuan kaiwa mahasiswa Fakultas Ilmu Kesehatan Universitas Islam Assyafiiyah mengalami peningkatan. Hal ini terlihat dari nili rata-rata yang diperoleh keteika pretest, yaitu 68, 1 dan nilai rata-rata yang diperoleh mahaiswa Fakultas Ilmu Kesehatan Universitas Assyafiiyah mengalami peningkatan menjadi 83,1 . Berdasarkan hal itu penulis dapat menyimpulkan bahwa metode role play efektif dalam meningkatkan kemampuan berbicara Bahasa Jepang mahasiswa Fakultas Ilmu Kesehatan Universitas Assyyafiiyah.

\begin{tabular}{|c|c|c|c|c|c|}
\hline \multicolumn{6}{|c|}{ Pretest } \\
\hline & & Frequency & Percent & Valid Percent & Cumulative Percent \\
\hline Valid & 50 & 1 & 4.5 & 5.0 & 5.0 \\
\hline & 55 & 2 & 9.1 & 10.0 & 15.0 \\
\hline & 60 & 2 & 9.1 & 10.0 & 25.0 \\
\hline & 65 & 3 & 13.6 & 15.0 & 40.0 \\
\hline & 68 & 3 & 13.6 & 15.0 & 55.0 \\
\hline & 70 & 3 & 13.6 & 15.0 & 70.0 \\
\hline & 73 & 1 & 4.5 & 5.0 & 75.0 \\
\hline & 75 & 3 & 13.6 & 15.0 & 90.0 \\
\hline & 85 & 1 & 4.5 & 5.0 & 95.0 \\
\hline & 90 & 1 & 4.5 & 5.0 & 100.0 \\
\hline & Total & 20 & 90.9 & 100.0 & \\
\hline Missing & System & 2 & 9.1 & & \\
\hline Total & & 22 & 100.0 & & \\
\hline
\end{tabular}

Gambar 1. Nilai Pretest SPSS

\begin{tabular}{|c|c|c|c|c|c|}
\hline \multicolumn{6}{|c|}{ Postest } \\
\hline & & Frequency & Percent & Valid Percent & Cumulative Percent \\
\hline Valid & 65 & 1 & 4.5 & 5.0 & 5.0 \\
\hline & 75 & 1 & 4.5 & 5.0 & 10.0 \\
\hline & 78 & 1 & 4.5 & 5.0 & 15.0 \\
\hline & 80 & 3 & 13.6 & 15.0 & 30.0 \\
\hline & 82 & 3 & 13.6 & 15.0 & 45.0 \\
\hline & 83 & 4 & 18.2 & 20.0 & 65.0 \\
\hline & 84 & 1 & 4.5 & 5.0 & 70.0 \\
\hline & 85 & 1 & 4.5 & 5.0 & 75.0 \\
\hline & 88 & 1 & 4.5 & 5.0 & 80.0 \\
\hline & 90 & 1 & 4.5 & 5.0 & 85.0 \\
\hline & 92 & 1 & 4.5 & 5.0 & 90.0 \\
\hline & 95 & 1 & 4.5 & 5.0 & 95.0 \\
\hline & 98 & 1 & 4.5 & 5.0 & 100.0 \\
\hline & Total & 20 & 90.9 & 100.0 & \\
\hline Missing & System & 2 & 9.1 & & \\
\hline Total & & 22 & 100.0 & & \\
\hline
\end{tabular}

Gambar 2. Tabel nilai postest SPSS 


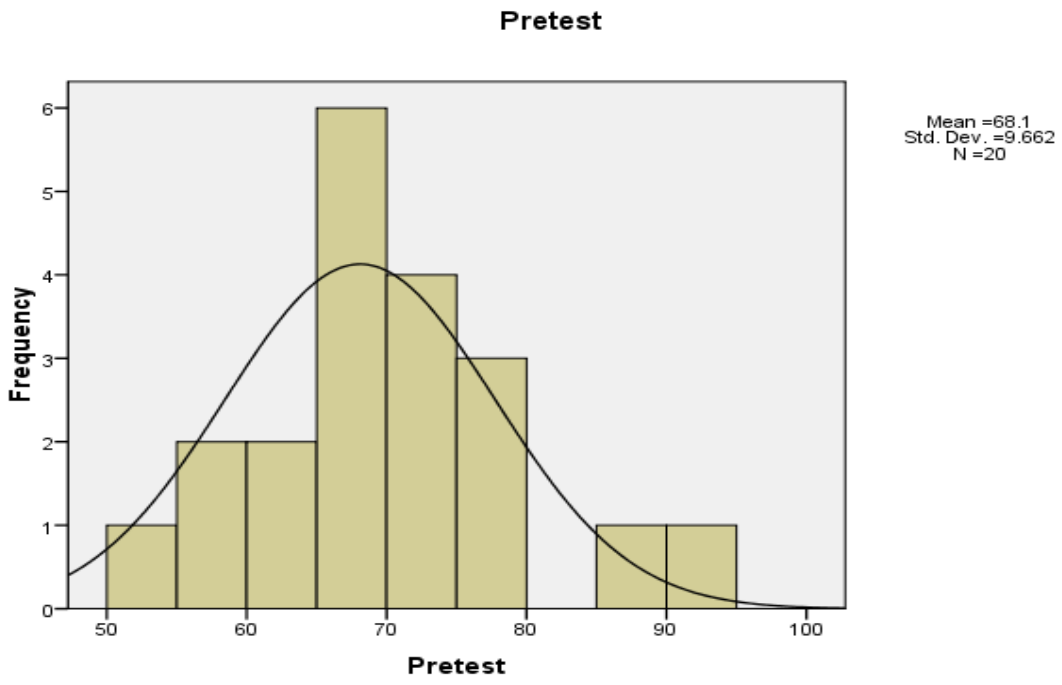

Gambar 3. Garfik SPSS Pretest Kaiwa

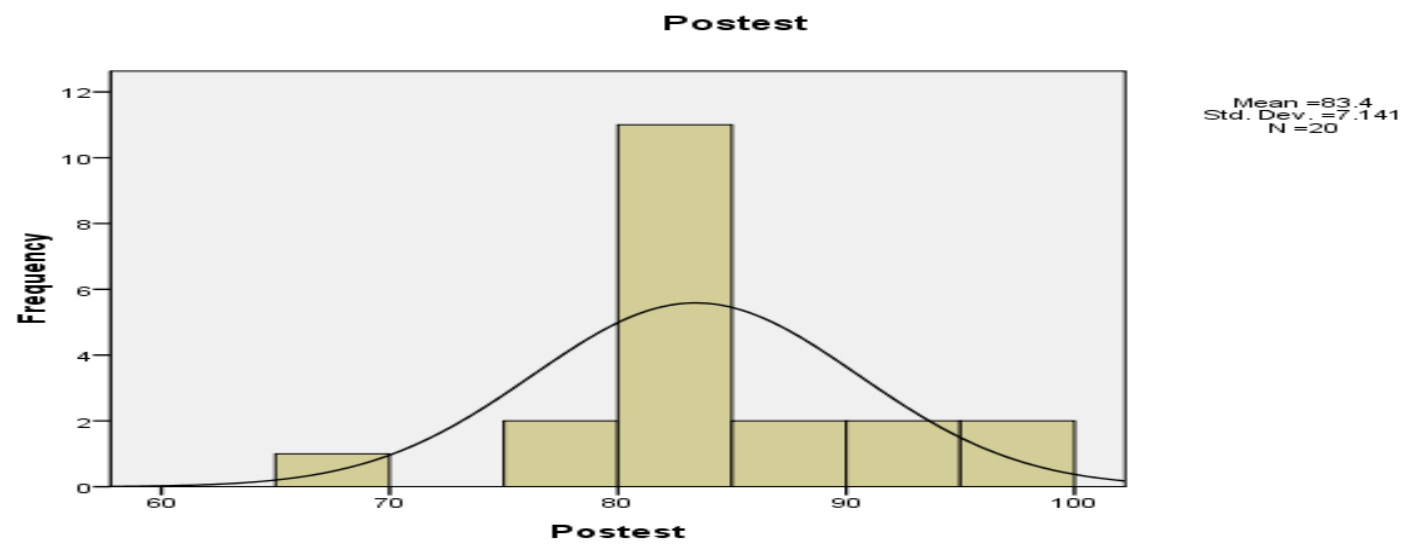

\section{Gambar 4. Grafik SPSS Nilai Postest}

Berdasarkan grafik-grafik SPSS diatas, dapat digambarkan bahwa nilai yang paling banyak muncul adalah nilai 65, 68, 70 dan 75 dengan frekuensi masing-masing 3 . Sementara pada saat post-test nilai yang yang paling banyak muncul adalah , meningkat, yaitu 83 dengan frekuensi 4.

\section{PEMBAHASAN}

\section{Treatment}

Pada penelitian ini penulis melakukan Treatment selama 5 kali, dengan tema tema kartu peran yang berbeda-beda:

1. Treatment 1 penulis memberikan perlakuan pada objek penelitian dengan menentukan tema langsung tanpa menggunakan kartu peran. Peneliti menunjuk beberapa siswa maju ke depan kelas, dan langsung memberikan tema saat itu juga pada siswa-siswanya. Siswa yang sudah berpasangan tersebut diberikan waktu untuk membuat naskah kaiwa terlebih dahulu menggunakan tema yang sudah penulis tentukan. Setelah itu siswa-siswa tersebut langsung melakukan role play. 
2. Treatment ke 2 peneliti memberikan perlakukan dengan mulai memberikan kartu peran yang sudah penliti siapkan terlebih dahulu. Tema-tema yang diberikan pada treatment ke 3 ini hanya dua tema yaitu: (1) tema menjadi perawat dan dokter di Rumah sakit. (2.) Tema menjadi perawat dan petugas di Panti Jumpo.

3. Treatment 3 peneliti memberi tema yang bermacam-macam dan sudah mulai menggunakan kartu peran. Tema-tema di treatment ke 3 terdiri dari: Bank, pasar, salon, barbershop, restoran dan perpustakaan.

4. Treatment ke 4 peneliti hanya memberikan 1 tema, yaitu tema di Panti Jompo. Karena mau melihat sejauh mana kemampuan siswanya dengan 1 tema ini. Bagaimana mahasiswa-mahasiswa tersebut dapat mengembangkan kalimat dengan menggunakan kosakata yang berhubungan panti Jompo. Alasan lain karena rencana tempat bekerja mahasiswa-mahasiswa tersebut di Jepang adalah di Panti Jompo. Hal ini agar membiasakan mereka ketika sudah bekerja di Panti Jompo sudah paham bagaimana melayani pasen-pasen panti jompo dengan berbicara bahasa Jepang yang berhubungan kosakata kesehatan dan panti Jompo.

5. Treatment ke 5 peneliti memberikan tema berupa wawancara dan mahasiswa tersebut diberikan kartu peran berbahasa Indonesia yang mengarahkan mahasiswamahasiswa tersebut saling tanya jawab menggunakan bahasa Jepang. Hal ini peneliti lakukan agar mahsiswa - mahasiswa tersebut terbiasa dengan peckapan tanya jawab dalam Bahasa Jepang. Apalagi biasanya sebelum berangkat ke jepang akan ada sesi wawancara menggunakan Bahasa Jepang kepada dari pihak agen yang ada di Jepang

\section{Kelebihan-kelebihan metode role play menggunakan role card}

Selama peneliti mempraktekan metode role play menggunakan role card ini, peneliti mengamati apa saja kelebihan dari metode ini. Diantaranya adalah:

1. Metode role play menggunakan kartu peran sangat praktis dilakukan, mahasiswa dapat mengembangakan kalimat dari petunjuk yang ada di kartu peran yang sudah pengajar siapkan.

2. Metode role play menggunakan role card cocok diterapkan pada pembelajar yang disiapkan untuk bekerja di Jepang. Karena melalui metode ini siswa membuat kemampuan pecakapan siswa terasah.

3. Metode role play menggunakan role card membuat siswa mandiri dalam melakukan latihan kaiwa, karena antara pemegang kartu pearan A maupun kartu peran, masingmasing tidak mengetahui isi kartu peran dari lawan bicaranya.

Kekurangan metode role play menggunakan role card

Pembuatan kartu peran yang sangat memakan waktu, karena kartu peran yang dibaut untuk 1 tema ada dua kartu peran, yaitu kartu peran A dan Kartu peran B. Hal ini tentu saja memakan waktu. Apalagi 1 tatap muka jika harus membat lebih dari 5 tema percakapan.

1. Penggunaan role card ketika praktek percakapan terkadang masalah jika kartu peran yang pengajar siapkan, kalimat - kalimat petunjuknya / klu tidak dapat dipahami mahasiswa.

2. Terkadang jika siswanyabtidak jeli membaca perintah yang ada di setiap kartu perannya, membuat percakapannya jadi tidak nyambung dan kadang-kadang juga membuat isi percakapannya tidak menarik. 
AKSARA: Jurnal Ilmu Pendidikan Nonformal

P-ISSN 2407-8018 E-ISSN 2721-7310 DOI prefix 10.37905

Volume 08, (1) January, 2021

http://ejurnal.pps.ung.ac.id/index.php/Aksara

\section{Hasil angket}

1 .

Saya pikir metode pembelajaran Kaiwa menggunakan metode role play dengan role card sebagai media pembelajarannya sangat menyenangkan.

20 jawaban

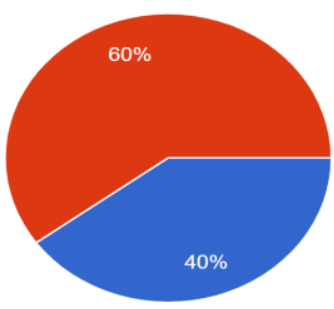

$$
\begin{aligned}
& \text { Sangat Setuju } \\
& \text { Setuju } \\
& \text { Tidak Setuju } \\
& \text { Sangat Tidak Setuju }
\end{aligned}
$$

Ragu-ragu

Berdasrkan hasil respons angket diatas, dapat penulis simpulkan, bahwa metode role play menggunakan role card/kartu peran merupakan metode pembelajaran yang menyenangkan siswa.

2.

Saya pikir pembelajaran Kaiwa menggunakan metode Role play dengan role card sebagai media pembelajarannya dapat meningkatkan kemampuan berbicara bahasa Jepang.

20 jawaban
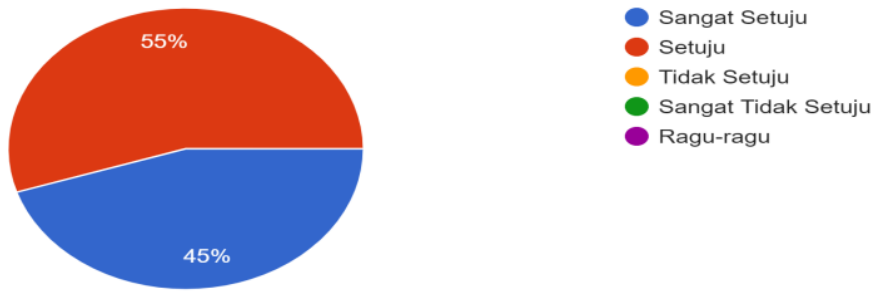

Berdasasrkan respon angket nomor 2, penulis dapat simpulkan kalau metode role play menggunakan role card efektif dalam meningkatkan kemampuan siswa dalam berbicara bahasa Jepang. Karena melalui bermain peran, membuat siswa tersebut dapat mengembanagkan tema kaiwa yang diberikan gurunya menjadi sebuah percakapan. 3.

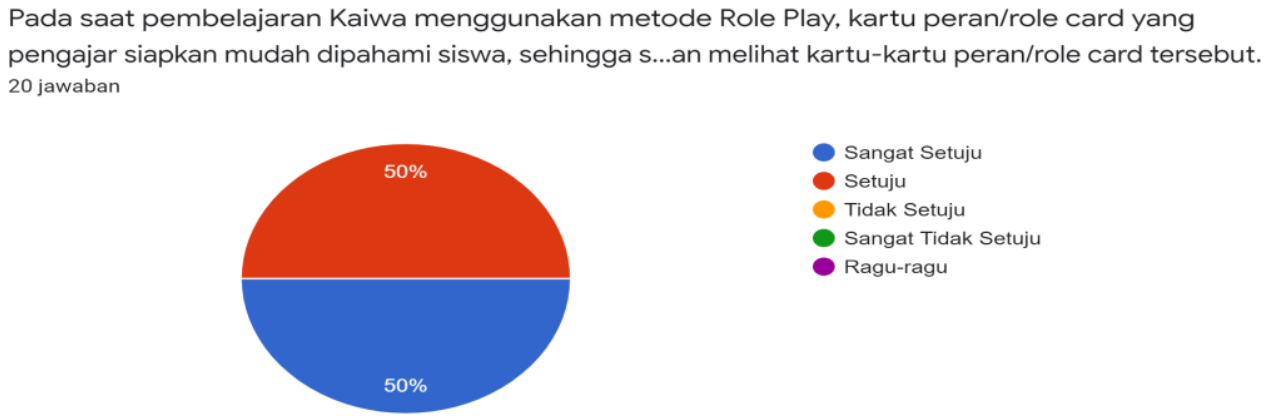

Berdasarkan respons angket dari penyataan noor 4, bahwa guru ketika menyruh siswanya melakukan latihan sesustu, guru harus memberikan contoh kepada siswasiswanya. Sehingga tidak membuat kebingungan siswanya. Apalagi metode yang 
digunakan bukan metode yang umum, sehingga guru memiliki peranan penting dalam mengarahkan siswanya agar dapat berlatih kaiwa dengan baik dan benar.

4.

Kesulitan pembelajaran Kaiwa menggunakan metode role play dengan Role card sebagai media pembelajarannya adalah pada penyusunan kalimat bahasa Jepang.

20 jawaban

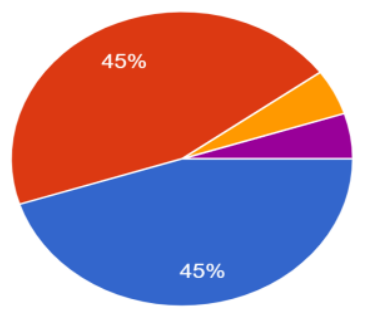

$$
\begin{aligned}
& \text { Sangat Setuju } \\
& \text { Setuju } \\
& \text { Tidak Setuju } \\
& \text { Sangat Tidak Setuju } \\
& \text { Ragu-ragu }
\end{aligned}
$$

Berdasarakan respon angket nomot 4, dapat disimpulkan bahwa kesulitan siswa dalam melakukan percakapan bahasa jepang perangkaian kalimat yang mudah dipahami lawan bicara, siswa banyak yang merasakan kesulitan dalam mengembanagan kalimat bahasa Jepang. Sehingga banyak siswa yang grogi ketika harus latihan percakapan di depan kelas atau meeting.

5 .

Minimnya perbendaharaan kosakata bahasa Jepang merupakan hal yang menyulitkan dalam pembelajaran kaiwa menggunakan metode role pla...ard/kartu peran sebagai media pembelajarannya. 20 jawaban
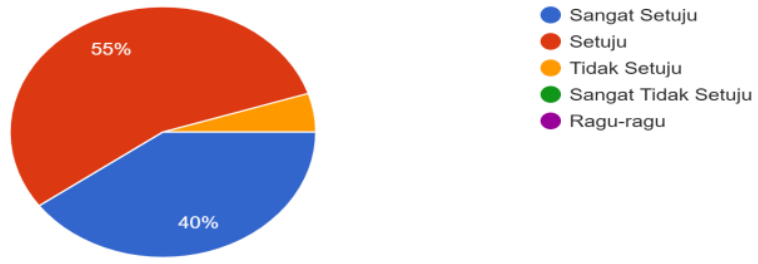

Berdasarkan respon angket nomor 5, yang membuat siswa kesulitan dalam melakukan percakapan adalah dikarenakan penguasaan kosakata siswa yang masih kurang, sehingga ketika praktek latihan percakapan membuat sswa tersebut tidak dapat mengembangkan kalimatnya.

6.

Tema-tema kaiwa yang pengajar siapkan di setiap role card variatif dan memudahkan dalam praktek percakapannya.

20 jawaban

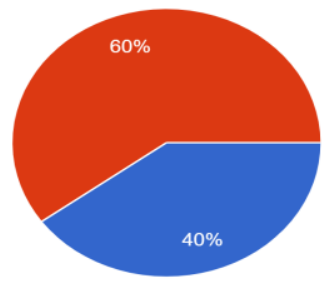

$$
\begin{aligned}
& \text { Sangat Setuju } \\
& \text { Setuju } \\
& \text { Tidak Setuju } \\
& \text { Sangat Tidak Setuju } \\
& \text { Ragu-ragu }
\end{aligned}
$$


Berdasarkan respon angket nomor 6, dapat disimpulkan bahwa tema-tema percakapan yang diberikan pengajarnta di setipan pelajaran sangat variatif, sehingga membuat siswanya menjadi bersemangat dalam melakukan percakapan bahasa Jepang. 7.

Saya pikir pada saat pembelajaran Kaiwa pengajar memberikan contoh bagaimana cara pembelajaran kaiwa menggunakan role card/kartu peran.

20 jawaban

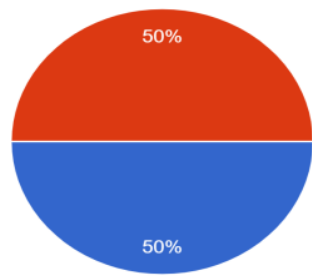

$$
\begin{aligned}
& \text { Sangat Setuju } \\
& \text { Setuju } \\
& \text { Tidak Setuju } \\
& \text { Sangat Tidak Setuju }
\end{aligned}
$$

- Ragu-ragu

Berdasarkan respon angket momor 7, dapat penulis simpulkan guru selalu memberikan contoh bagaimana latihan percakapan yang baik dan bener menggunaan kartu peran.

8.

Pembelajaran Kaiwa menggunakan metode Role Play dengan Role card/kartu peran sebagai media pembelajarannya membuat motivasi belajar kaiwa meningkat.

20 jawaban

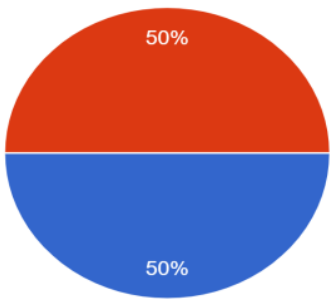

Ragu-ragu

Berdasarkan respon angket diatas, dapat penuli ssimpulakna bahwa metode role play dengan role card membuat motivasi siswa menjadi meningkat.

9.

Saya pikir sebelum menggunakan metode role play dengan Role card/kartu peran sebagai media pembelajaran, kemampuan berbicara bahasa Jepang saya masih kurang. 20 jawaban
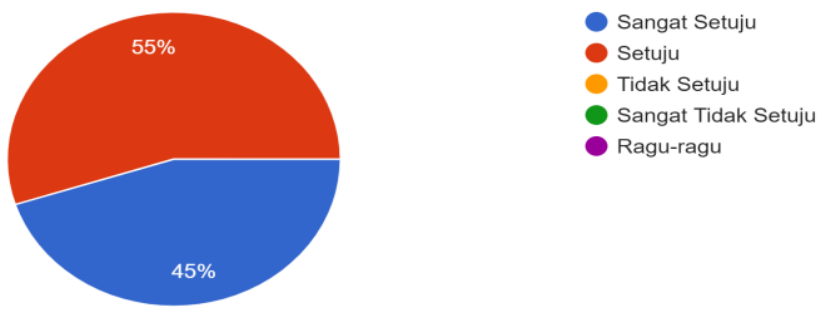

Berdasarkan respon angket nonor 9, penulis dapat simpulkan bahwa sebelum menggunaan metode role play dalam latihan percakapan, kemampuan siswa dalam 
melakukan percakaan masih kurang. Akan tetapi, setelah menggunakan metode role play. Kemampuan siswa dalam berbicara menjadi meningkat.

\section{KESIMPULAN}

Dari hasil penelitian yang penulis parkatekan di Fakultas Ilmu Kesehatan Universitas Assyafiiyah menggunakan metode role play. Penulis dapat simpulkan sebgai berikut:

1. Metode role play menggaunakan role card dapat meningkatkan kemampuan berbicara bahasa Jepang. Hal ini terlihat dari hasil nilai yang didapat mahasiswa Ketika dilakukan pretest nilai rata-rata yang didapat mahasiswa cukup $(68,1)$. Tetapi, setelah dilakukan treatment kemampuan berbicara mahasiswa menjadi meningkat menjadi katagori sangat baik $(83,4)$. Jadi, dapat disimpulkanbahwa metode role play dapat meningkatkan kemampuan mahasiswa Fakultas Ilmu Kesehatan Univerasitas Assyafiiyah.

2. Kemampuan berbicara Bahasa Jepang mahasiswa mahasiswa Fakultas Ilmu Kesehatan Universitas Islam Assyafiiyah sebelum mengunakan metode Role Play masih kurang dalam katagori cukup $(68,1)$, tetapi setelah ,emggunakan metode role play kemmapuan berbicara mahasiswa meningkat menjadi katagori sangat baik $(83,1)$. Hal ii juga terlihat dari respon angket Ketika diberi kalimat pernyataan kemampuan berbicara siswa meningkat setelah menggunakan metode role play. Didapat jawaban 50 persen menjawab setuju dan 50 persen sangat setuju.

Berdasarkan hasil penelitian menggunakan metode role play yang sudah dilaksanakan, penulis ada saran mengenai pembelajaran kaiwa menggunakan metode role play. Diharapkan guru atau dosen yang akan menggunakan metode role play dengan menggunakan property role card. Guru/dosen harus menyipakan kartu perannya dengan baik dan benar, buat kartu pearan yang muadah dipahami oleh siswanya.

\section{DAFTAR PUSTAKA}

Chaer, Abdul. 2015. Psikolinguistik - Kajian Teori. Rineka Cipta. Bandung

Hidayat, Ahmad, Asep. 2006. Filsafat Bahasa Mengungkap Hakikat Bahasa, Makna dan Tanda. Rosda Bandung

Iskandarwassid dan Sunendar. 2008. Strategi Pembelajaran Bahasa, Rosda : Bandung

Sudjianto. 2010. Motodologi Pembelajaran Ketrampilan Berbahasa Jepang. Bekasi: Kessaint Blanc.

Ningsih, Sadyana \& Hermawan. 2019. Implemaentasi Roleplay Dalam Pembelajaran Bahasa Jepang oleh Guru SMK Negeri 1 Singaraja. Jurnal Pendidikan Bahasa Jepang Universitas Pendidikan Ganesha, Bali.

Nurwida, Martin. 2016. Peningkatan Keterampilan Berbicara melalui Storytelling untuk Sekolah Dasar. Jurnal Ilmiah Guru COPE

Restoeningroem,. 2014. Teknik Role Play terhadap pembelajaran berbicara bahasa Jepang. E Journal WIDYA Non - Eksakta

Soemarmi, Kertajati. 2017. Upaya Meningkatkan Kemampuan Berbicara Bahasa Jepang melalui Metode Bermain Peran (Role Play). BRILIANT: Jurnal Riset dan Konseptual

Toliwongi, Mariam. 2021. Strategi Pembelajaran Bahasa Jepang "Kaiwa” Syntax Literate: Jurnal Ilmiah Indonesia 